\title{
Predictors of Routine Dental Check-up Among Male Adolescents in Saudi Arabia
}

\section{Čimbenici rutinskih stomatoloških pregleda među mladićima u pubertetu u Saudijskoj Arabiji}

College of Dentistry, Imam Abdulrahman Bin Faisal University, Dammam, Saudi Arabia.

Stomatološki fakultet Sveučilišta imama Abdulrahmana Bin Faisala, Dammam, Saudijska Arabija

\section{Abstract}

Objective: To evaluate the association of socioeconomic factors and self-perceived oral conditions with routine dental check-up among male adolescents. Methods: This cross-sectional study was conducted on male children (grade 10-12) from public schools in different cities of the Eastern province of Saudi Arabia. A multistage random sampling was used for the recruitment of study participants. A piloted questionnaire translated into the Arabic language was used for data collection. Results: There were 586 students with mean age $16.86 \pm 0.87$ years. The prevalence of routine dental visit within last year was $18.9 \%$. Half of the entire sample had dental cavities $(50.5 \%)$ and tooth sensitivity $(50 \%)$ followed by dental pain (42.2\%). Bivariate analyses found that the children with dental cavities (OR 0.4, $95 \% \mathrm{Cl} 0.26,0.61)$, dental pain (OR $0.63,95 \% \mathrm{Cl} 0.41,0.97$ ), and malodor (OR $0.41,95 \% \mathrm{Cl} 0.23$, 0.71 ) had significantly lower odds of routine dental visits than those without these conditions. The final model of multivariable logistic regression showed that dental cavities (OR $0.42,95 \% \mathrm{Cl} 0.27$, 0.66 ) and malodor (OR $0.45,95 \% \mathrm{Cl} 0.25,0.78)$ were significantly associated with lower likelihood of visiting dental office for a regular dental check-up. No significant influence of socioeconomic factors on routine dental attendance was observed. Conclusions: A small proportion of children performed routine dental visits. The children with dental cavities and malodor were less likely to perform routine dental visits. The awareness about the importance of regular dental check-up should be raised to reduce the burden of oral diseases in schoolchildren.
Received: March 29, 2019

Accepted: July 28, 2019

Address for correspondence Muhammad Ashraf Nazir, BSc, BDS, MPH, FRSPH

Lecturer Dental Public Health, Imam çAbdulrahman Bin Faisal University

College of Dentistry

Department of Preventive Dental

Science,

Dammam, Saudi Arabia.

P. O. Box 1982 Dammam 31441

Cellphone\#00966543579615

manazir@iau.edu.sa

Key words

Dental Care; Self-Examination; Socioeconomic Factors

\section{Introduction}

Routine dental visits are important for the maintenance of good oral health which is an integral component of systemic health $(1,2)$. Low caries experience, reduced periodontal destruction, and low tooth loss are common in routine dental attenders $(1,3)$. It is also known that dental attendance in post-childhood is associated with improved dental health in adulthood (4). Similarly, better oral health selfperception and improved oral health-related quality of life are associated with routine dental attendance $(5,6)$. Regular dental attendance provides an opportunity for early diagnosis of oral conditions, provision of preventive dental services, and timely treatment of dental problems $(4,7)$. A regular oral examination is also important for oral cancer prevention as patients with oral cancer who visit the dentist once a year demonstrate reduced tumor stage and improved health-related quality of life (8).

There is an ongoing scientific debate in the international scientific community about the frequency of dental visits because oral health needs, medical and dental history, and

\section{Uvod}

Rutinski posjeti stomatologu važni su za održavanje dobrog oralnoga zdravlja koje je dio sistemskoga zdravlja (1, 2). Manja prevalencija karijesa, manje parodontnih oštećenja i manji gubitak zuba uobičajeni su kod pacijenata koji rutinski odlaze na stomatološke preglede $(1,3)$. Također je poznato da je posjet stomatologu u pubertetu povezan $s$ boljim zdravljem zuba u odrasloj dobi (4). Slično tomu, bolja percepcija oralnoga zdravlja i poboljšana kvaliteta života, vezana uz oralno zdravlje, povezani su s rutinskim odlascima stomatologu $(5,6)$. Redovite stomatološke kontrole omogućuju ranu dijagnozu patoloških promjena, preventivne tretmane i pravodobno liječenje oralno-zdravstvenih problema $(4,7)$. Redoviti pregledi važni su i za prevenciju oralnoga raka jer pacijenti s tom bolešću, ako posjećuju stomatologa jedanput na godinu, imaju niži stadij tumora pri njegovu otkrivanju i poboljšanu kvalitetu života povezanu sa zdravljem (8).

U međunarodnoj znanstvenoj zajednici u tijeku je rasprava o učestalosti stomatoloških posjeta jer se stanje oralnoga 
disease risk level vary from individual to individual $(9,10)$. However, dental practitioners in many developed countries advocate dental check-up within six months (10). American Dental Association also recommends regular dental visits once or twice a year, depending upon unique oral needs of each individual (11). In the U.K, the National Institute of Health and Care Excellence (NICE) provides guidelines about the routine dental check-up and recommends the longest interval of 12 months between oral health examinations for patients under the age of 18 years (12).

There are some reports about the factors associated with routine dental attendance among pre-school and primary schoolchildren and adults $(3,13,14)$. Camargo et al. identified income and education and preventive guidance of mothers as main predictors of dental visits for the routine dental check-up in Brazilian preschool children (14). A study by John et al. found that private insurance and age of children were significant predictors of routine dental attendance in primary schoolchildren in Australia (13). Amarasena et al. conducted a study on Aboriginal Australians adults and observed that younger age and having no health problems were associated with performing routine dental visit (3).

The data about regular dental visits are important for the reduction of oral disease burden and maintenance of optimal oral and systemic health. However, the literature lacks baseline data about the socioeconomic and oral health-related factors that influence routine dental visits among adolescents. Therefore, it was hypothesized that routine dental attendance is associated with socioeconomic factors and dental problems among adolescents. The aim of this study was to evaluate the factors associated with routine dental attendance among male adolescents in Saudi Arabia.

\section{Material and methods}

The study includes secondary analyses of data from a project related to oral health of adolescents. The ethics committee at the College of Dentistry, Imam Abdulrahman Bin Faisal University approved the project (EA\# 2018009). Grade 1012 male students (age 16-18 years) from public high schools in Dhahran, Al-Khobar, and Dammam cities participated in the study. Random selection of seven schools in these cities was carried out using a lottery method. Microsoft Excel 2010 random number generator was used to select classes and students from these schools. The administrators of selected schools provided permission to conduct the study in their respective institutions.

Data collection was carried out by using a piloted questionnaire in the Arabic language. The questionnaire was first developed in the English language and rigorously reviewed to ensure its content validity. It was then translated into the Arabic language according to the guidelines of World Health Organization (WHO) about translation and adaptation of instrument (15). Later, it was administered among 30 students for pilot testing. Based on their feedback, minor mod- zdravlja, medicinska i stomatološka anamneza te razina rizika od bolesti razlikuju od pojedinca do pojedinca $(9,10)$. No liječnici dentalne medicine u mnogim razvijenim zemljama zauzimaju se za preglede svakih šest mjeseci (10). Američka stomatološka udruga također preporučuje redovite posjete jedanput ili dva puta na godinu, ovisno o potrebama svakog pojedinca (11). U Velikoj Britaniji je Nacionalni institut za izvrsnost u zdravstvu (NICE), tijelo koje daje smjernice o rutinskim stomatološkim pregledima, preporučio najdulji interval od 12 mjeseci između dvaju pregleda za pacijente mlađe od 18 godina (12).

Postoje izvješća o čimbenicima povezanima s rutinskim odlascima stomatologu među predškolskom djecom, osnovnoškolcima i odraslima $(3,13,14)$. Camargo i suradnici istaknuli su prihode i obrazovanje te preventivno usmjeravanje majki kao glavne čimbenike stomatoloških posjeta radi rutinskih pregleda među brazilskom djecom predškolske dobi (14). Istraživanje Johna i suradnika otkrilo je da su privatno osiguranje i dob djece važni čimbenici za rutinski odlazak stomatologu kod osnovnoškolaca u Australiji (13). Amarasena i suradnici proveli su istraživanje na odraslim Aboridžinima, dakle, također u Australiji, i uočili da je mlađa dob, bez zdravstvenih problema, povezana s obavljanjem rutinskih stomatoloških posjeta (3).

Podatci o redovitim posjetima stomatologu važni su za smanjenje prevalencije oralnih bolesti i održavanje optimalnoga oralnog i sistemskog zdravlja. No u literaturi nema osnovnih podataka o socijalno-ekonomskim i oralno-zdravstvenim čimbenicima koji utječu na rutinske stomatološke preglede među adolescentima. Zato se pretpostavlja da je rutinski odlazak stomatologu povezan sa socijalno-ekonomskim čimbenicima i dentalnim problemima djece u pubertetu. Cilj ovog istraživanja bio je procijeniti čimbenike povezane s rutinskim posjetima stomatologu među mladićima u pubertetu u Saudijskoj Arabiji.

\section{Materijali i metode}

Istraživanje je uključivalo sekundarne analize podataka iz projekata koji se odnose na oralno zdravlje adolescenata. Odbor za etiku na Stomatološkog fakulteta Sveučilišta imama Abdulrahmana Bin Faisala odobrio je projekt (EA \# 2018009). U istraživanju su sudjelovali učenici od 10. do 12. razreda (u dobi od 16 do 18 godina) iz javnih srednjih škola u Dhahranu, Al-Khobaru i Dammamu. U tim gradovima nasumično je odabrano sedam škola. Za odabir razreda i učenika korišten je Microsoft Excel 2010. - generator slučajnih brojeva. Dopuštenje za istraživanje dali su ravnatelji u tim obrazovnim ustanovama.

Podatci su prikupljeni korištenjem pilotiranog upitnika na arapskome jeziku. Upitnik je preveden s engleskoga i temeljito je pregledan kako bi se osigurala valjanost sadržaja. Zatim je preveden na arapski prema smjernicama Svjetske zdravstvene organizacije (WHO-a) o prijevodu i prilagodbi instrumenta (15). Poslije je primijenjen na 30 učenika u sklopu pokusnog testiranja. Na temelju povratnih informacija, u tekstu su učinjene manje izmjene. Podatci tih učenika nisu uključeni u statističku analizu ovog istraživanja 
ifications were made in the instrument. The data of these students were not included in the statistical analysis of the study.

The questionnaire inquired information about demographic variables, routine dental check-up, and self-perceived oral conditions. The schoolchildren were asked about having dental pain, dental cavities, bleeding gums, tooth sensitivity, oral malodor, and dryness of mouth. In addition, information about smoking was also sought. Ethical standards were maintained during the conduct of the study. Informed consent was obtained from the parents of the study participants. The schoolchildren were provided with the details of the study and its potential benefits. They were informed about their voluntary participation in the study. The ambiguity in understanding the questions was addressed by ensuring effective communication during questionnaire administration. The questionnaire was provided to those who were willing to participate in the survey. The study was conducted according to the principles of Helsinki Declaration.

SPSS software (IBM SPSS Statistics for Windows, version 22.0. Armonk, NY: IBM Corp) was used for data analyses. Descriptive statistics included frequency, percentage, and 95\% confidence interval. Bivariate and multivariable logistic regression analyses were performed to investigate the influence of independent variables on the dependent variable, routine dental check-up. Independent variables included academic grades in previous year, monthly family income, father's education level, mother's education level, having dental cavities, bleeding gums, tooth sensitivity, oral malodor, dryness of mouth, and smoking habit. In addition, the final best model was created using backward LR selection method due to its good predictive power. A p-value of $<0.05$ was considered statistically significant.

\section{Results}

There were 586 children in the study and their mean age was $16.86 \pm 0.87$ years. The prevalence of routine dental attendance during the last 12 months was $18.9 \%(\mathrm{n}=111)$. Most children $(n=493,84.1 \%)$ scored more than $80 \%$ grades in previous academic year. The majority of children had university-educated parents. About two-thirds $(\mathrm{n}=401,68.4 \%)$ had a monthly family income of less than 10,000 SAR (equivalent to $\$$ U.S. 2665). Half of the sample had dental cavities $(\mathrm{n}=296,50.5 \%)$ and tooth sensitivity $(\mathrm{n}=293,50 \%)$ followed by dental pain $(n=247,42.2 \%)$. Approximately, one-third of them had bleeding gums and oral malodor (Table.1).

Table 2 demonstrates the influence of individual socioeconomic factors and perceived oral conditions on routine dental check-up among schoolchildren. Bivariate statistical analyses revealed significant associations between having dental cavities, tooth sensitivity, malodor and regular dental visits. The children with dental cavities $(\mathrm{OR}=0.4,95 \%$ $\mathrm{CI}=0.26,0.61)$, dental pain $(\mathrm{OR}=0.63,95 \% \mathrm{CI}=0.41$, $0.97)$, and malodor $(\mathrm{OR}=0.41,95 \% \mathrm{CI}=0.23,0.71)$ had significantly lower odds of performing routine dental visits. No significant influence of academic grades, family income, and parental education was observed.
Upitnikom su prikupljene informacije o demografskim varijablama, rutinskim stomatološkim pregledima i samopercipiranim oralnim uvjetima. Učenici su odgovarali na pitanja o bolovima, karijesu, krvarenju desni, osjetljivosti zuba, zadahu i suhoći usta. Uz to, prikupljali su se i podatci o pušenju. Tijekom istraživanja poštovali su se etički standardi. Informirani pristanak dobiven je od roditelja svih sudionika $\mathrm{u}$ istraživanju. Učenicima je detaljno objašnjeno istraživanje i moguća korist. Obaviješteni su da sudjeluju dobrovoljno. Nejasnoće u razumijevanju pitanja riješene su učinkovitom komunikacijom tijekom njegova ispunjavanja. Upitnik je dan onima koji su htjeli sudjelovati u anketi. Istraživanje je provedeno prema načelima Helsinške deklaracije.

$\mathrm{Za}$ analizu podataka korišten je softver SPSS (IBM SPSS Statistika za Windowse, verzija 22,0. Armonk, NY: IBM Corp). Primijenjena statistika uključivala je učestalost, postotak i interval pouzdanosti od $95 \%$. Provedene su bivarijantne i multivarijantne logističke regresijske analize kako bi se ispitao utjecaj neovisnih varijabli na ovisnu varijablu - rutinski stomatološki pregled. Neovisne varijable uključivale su školske ocjene u prethodnoj godini, mjesečni dohodak u obitelji, razinu obrazovanja oca, razinu obrazovanja majke, karijese, krvarenje desni, osjetljivost zuba, zadah, suhoću usta i naviku pušenja. Tako je konačni najbolji model stvoren korištenjem reverzne LR metode odabira zbog svoje dobre mogućnosti predviđanja. Vrijednost $\mathrm{p}<0,05$ smatrala se statistički značajnom.

\section{Rezultati}

U istraživanju je sudjelovalo 586 mladića prosječne dobi $16,86 \pm 0,87$ godina. Prevalencija rutinskih posjeta stomatologu tijekom posljednjih 12 mjeseci iznosila je 18,9\% ( $\mathrm{n}=$ $111)$. Većina ispitanika $(n=493,84,1 \%)$ postigla je više od 80 $\%$ ocjena u prethodnoj školskoj godini. Većini su roditelji bili fakultetski obrazovani. Otprilike dvije trećine $(\mathrm{n}=401,68,4$ $\%$ živjelo je u obitelji s mjesečnim dohotkom manjim od 10 000 SAR-a (oko 2665 američkih dolara). Polovina mladića imala je karijes $(\mathrm{n}=296,50,5 \%)$ i osjetljive zube $(\mathrm{n}=293$, $50 \%$ ) praćene bolovima ( $\mathrm{n}=247,42,2 \%)$. Otprilike jednoj trećini krvarile su desni i imali su neugodan zadah (tablica 1.).

Tablica 2. pokazuje utjecaj pojedinih socijalno-ekonomskih čimbenika i samopercipiranih oralnih stanja na rutinske stomatološke kontrole kod školske djece. Bivarijantna statistička analiza pokazala je značajnu povezanost između karijesa, osjetljivosti zuba, neugodnog zadaha i redovitih posjeta stomatologu. Djeca s karijesom $(\mathrm{OR}=0,4,95 \% \mathrm{CI}=0,26$, $0,61)$, zuboboljom $(\mathrm{OR}=0,63,95 \% \mathrm{CI}=0,41,0,97) \mathrm{i}$ zadahom $(\mathrm{OR}=0,41,95 \% \mathrm{CI}=0,23,0,71)$ imala su znatno lošije izglede za odlazak stomatologu na rutinske preglede. Nije uočen znatniji utjecaj školskih ocjena, obiteljskih prihoda i obrazovanja roditelja. 
Table 1 Descriptive statistics of study participants

Tablica 1. Deskriptivna statistika sudionika u istraživanju

\begin{tabular}{|c|c|c|}
\hline Variables $\bullet$ Varijabla & $\begin{array}{c}\mathrm{N} / \% \\
\mathrm{~N}=586\end{array}$ & $95 \% \mathrm{CI}$ \\
\hline Routine dental visits • Rutinski posjeti stomatologu & $111(18.9)$ & $(16,22.3)$ \\
\hline $\begin{array}{l}\text { Academic grades } \bullet \text { Akademske ocjene } \\
\text { More than } 80 \% \bullet \text { Više od } 80 \% \\
\text { Less than } 80 \% \bullet \text { Manje od } 80 \% \\
\end{array}$ & $\begin{array}{l}493(84.1) \\
93(15.9) \\
\end{array}$ & $\begin{array}{l}(80.9,86.8) \\
(13.1,19.1)\end{array}$ \\
\hline $\begin{array}{l}\text { Family income } \bullet \text { Obiteljski prihodi } \\
\quad \geq \text { SAR } 10000 \text { (Equal to US\$ 2665) } \bullet \geq 10000 \text { SAR-a (oko } 2665 \text { am. dol.) } \\
\quad<\text { SAR } 10000 \text { (Equal to US\$ 2665) }<10000 \text { SAR-a (oko } 2665 \text { am. dol.) }\end{array}$ & $\begin{array}{l}185(31.6) \\
401(68.4)\end{array}$ & $\begin{array}{l}(27.9,35.4) \\
(64.5,72.1)\end{array}$ \\
\hline $\begin{array}{l}\text { Father's education } \bullet \text { Obrazovanje oca } \\
\quad \geq \text { University education } \bullet \geq \text { fakultetsko obrazovanje } \\
\quad<\text { School education } \bullet<\text { srednja škola }\end{array}$ & $\begin{array}{l}393(67.1) \\
193(32.9)\end{array}$ & $\begin{array}{l}(63.1,70.7) \\
(29.2,36.8)\end{array}$ \\
\hline $\begin{array}{l}\text { Mother's education } \bullet \text { Obrazovanje majke } \\
\quad \geq \text { University education } \bullet \geq \text { fakultetsko obrazovanje } \\
\quad<\text { School education } \bullet<\text { srednja škola }\end{array}$ & $\begin{array}{l}366(62.5) \\
220(37.5)\end{array}$ & $\begin{array}{l}(58.4,66.3) \\
(33.7,41.5)\end{array}$ \\
\hline Smoking $\bullet$ Pušenje & $199(34.0)$ & $(30.2,37.9)$ \\
\hline Bleeding gums $\bullet$ Krvarenje desni & $180(30.7)$ & $(27.1,34.6)$ \\
\hline Dental cavities $\bullet$ Karijes & $296(50.5)$ & $(46.5,54.5)$ \\
\hline Dental pain $\bullet$ Zubobolja & $247(42.2)$ & $(38.2,46.2)$ \\
\hline Tooth sensitivity • Osjetljivost zuba & $293(50.0)$ & $(45.9,54.1)$ \\
\hline Dryness of mouth $\bullet$ Suhoća usta & $137(23.4)$ & $(20.1,27)$ \\
\hline Malodor $\bullet$ Zadah & $163(27.8)$ & $(24.3,31.6)$ \\
\hline Age $\bullet$ Dob & $\begin{array}{c}\text { Mean } \bullet \text { Prosjek }(S D) \\
16.86(0.87) \text { years } \bullet \text { godina }\end{array}$ & \\
\hline
\end{tabular}

Table 2 Bivariate analysis: Predictors of routine dental check-up among male adolescents

Tablica 2. Bivarijantna analiza: čimbenici rutinskih posjeta stomatologu među mladićima u pubertetu

\begin{tabular}{|c|c|c|}
\hline Variables $\bullet$ Varijabla & $\begin{array}{l}\text { Un-adjusted OR } \\
\text { Neprilagodeni OR } \\
\quad(95 \% \mathrm{CI})\end{array}$ & P-value $\bullet P$-vrijednost \\
\hline $\begin{array}{l}\text { Academic grades } \bullet \text { Akademske ocjene } \\
\text { More than } 80 \% \bullet \text { Više od } 80 \% \\
\text { Less than } 80 \% \cdot \text { Manje od } 80 \%\end{array}$ & $1.15(0.64,2.06)$ & 0.641 \\
\hline $\begin{array}{l}\text { Family income } \bullet \text { Obiteljski prihodi } \\
\geq \text { SAR } 10000 \text { (Equal to US\$ 2665) } \bullet \geq 10000 \text { SAR-a (oko } 2665 \text { am. dol.) } \\
<\text { SAR } 10000 \text { (Equal to US\$ 2665) } \bullet<10000 \text { SAR-a (oko } 2665 \text { a.. dol.) }\end{array}$ & $1.22(0.79,1.89)$ & 0.369 \\
\hline $\begin{array}{l}\text { Father's education } \bullet \text { Obrazovanje oca } \\
\quad \geq \text { University education } \bullet \geq \text { fakultetsko obrazovanje } \\
\quad<\text { School education } \bullet<\text { srednja škola }\end{array}$ & $1.27(0.81,1.99)$ & 0.307 \\
\hline $\begin{array}{l}\text { Mother's education } \bullet \text { Obrazovanje majke } \\
\quad \geq \text { University education } \bullet \geq \text { fakultetsko obrazovanje } \\
\quad<\text { School education } \bullet<\text { srednja škola }\end{array}$ & $0.94(0.61,1.44)$ & 0.773 \\
\hline Smoking $\bullet$ Pušenje & $1.29(0.84,1.98)$ & 0.238 \\
\hline Bleeding of gums in the past month $\bullet$ Krvarenje desni u proteklom mjesecu & $1.16(0.75,1.8)$ & 0.507 \\
\hline Dental cavities $\bullet$ Karijes & $0.4(0.26,0.61)$ & $<0.001^{*}$ \\
\hline Dental pain in the past month $\cdot$ Zubobolja u proteklom mjesecu & $0.63(0.41,0.97)$ & $0.037^{*}$ \\
\hline Tooth sensitivity in the past month $\bullet$ Preosjetljivost zuba u proteklom mjesecu & $0.71(0.47,1.08)$ & 0.114 \\
\hline Dryness of mouth $\bullet$ Suhoća usta & $1.07(0.66,1.73)$ & 0.794 \\
\hline Malodor $\bullet$ Zadah & $0.41(0.23,0.71)$ & $0.001^{*}$ \\
\hline
\end{tabular}

Multivariable logistic regression analysis showed that children with dental cavities and oral malodor were $43 \%$ and $39 \%$ respectively less likely to visit dental office for routine dental check-up than those without dental cavities and oral malodor $(\mathrm{P}<0.05)$ (tab. 3). All nine of two-way interac-
Multivarijabilna logistička regresijska analiza pokazala je da djeca s karijesom i neugodnim zadahom imaju $43 \%$, odnosno $39 \%$ manju vjerojatnost da će posjetiti stomatologa zbog rutinskog pregleda od onih bez karijesa i zadaha ( $\mathrm{P}<$ $0,05)$ (tablica 3.). Svih devet dvosmjernih interakcija stoma- 
Table 3 Multivariable logistic regression analysis: Predictors of routine dental check-up among male adolescents

Tablica 3. Multivarijantna logistička regresija: čimbenici rutinskih stomatoloških pregleda među mladićima u pubertetu

\section{Variables $\bullet$ Varijabla}

Un-adjusted OR •

Neprilagođeni OR

$(95 \% \mathrm{CI})$

Academic grades $\bullet$ Akademske ocjene
More than $80 \% \bullet$ Više od $80 \%$
Less than $80 \% \cdot$ Manje od $80 \%$

Family income $\bullet$ Obiteljski prihodi

$\geq$ SAR 10000 (Equal to US\$2665) • $\geq 10000$ SAR-a (oko 2665 am. dol.)

$<$ SAR 10000 (Equal to US\$ 2665) • < 10000 SAR-a (oko 2665 a,. dol.)

Father's education $\bullet$ Obrazovanje oca

$\geq$ University education $\bullet \geq$ fakultetsko obrazovanje

$<$ School education $\bullet<$ srednja škola

Mother's education $\bullet$ Obrazovanje majke

$\geq$ University education $\bullet \geq$ fakultetsko obrazovanje

$<$ School education $\bullet<$ srednja škola

\begin{tabular}{l|l}
\hline Smoking $\bullet$ Pušenje & \\
\hline Bleeding of gums in the past month $\bullet$ Krvarenje desni u proteklom mjesecu & \\
\hline Dental cavities $\bullet$ Karijes & \\
\hline Dental pain in the past month $\bullet$ Zubobolja u proteklom mjesecu & \\
\hline Tooth sensitivity in the past month $\bullet$ Preosjetljivost zuba u proteklom mjesecu & \\
\hline Dryness of mouth $\bullet$ Suhoća usta & \\
\hline Malodor $\bullet$ Zadah &
\end{tabular}

*Statistically significant $\bullet$ Statistički značajno

\begin{tabular}{|c|c}
\hline \multicolumn{1}{c|}{$(\mathbf{9 5 \%} \mathbf{C I})$} & 0.834 \\
\hline $1.07(0.57,2.01)$ & 0.542 \\
\hline $1.15(0.73,1.82)$ & 0.147 \\
\hline $1.45(0.88,2.41)$ & \\
\hline $0.75(0.46,1.23)$ & 0.261 \\
\hline $1.33(0.88,2.1)$ & 0.221 \\
\hline $1.53(0.94,2.5)$ & 0.085 \\
\hline $0.43(0.26,0.7)$ & $0.001^{*}$ \\
\hline $0.86(0.51,1.45)$ & 0.586 \\
\hline $0.85(0.53,1.37)$ & 0.515 \\
\hline $1.37(0.8,2.36)$ & 0.249 \\
\hline $0.39(0.21,0.7)$ & $0.002^{*}$ \\
\hline
\end{tabular}

\begin{tabular}{|c|c|c|}
\hline Variables $\bullet$ Varijable & $\begin{array}{c}\text { Un-adjusted OR } \\
\text { Neprilagodeni OR } \\
(95 \% \mathrm{CI})\end{array}$ & P-value $\bullet$ P-vrijednost \\
\hline 1. Dental cavities ${ }^{\mathrm{x}}$ malodor $\bullet$ karijes $^{\mathrm{x}}$ zadah & $0.61(0.51,0.74)$ & $<0.001^{*}$ \\
\hline 2. Dental cavities ${ }^{x}$ bleeding gums $\bullet$ karijes ${ }^{x}$ krvarenje desni & $0.78(0.65,0.93)$ & $0.006^{*}$ \\
\hline 3. Dental cavities ${ }^{x}$ pain $\bullet$ karijes ${ }^{x}$ bol & $0.73(0.62,0.87)$ & $<0.001^{*}$ \\
\hline 4. Dental cavities ${ }^{\mathrm{x}}$ sensitivity $\cdot$ karijes $^{\mathrm{x}}$ osjetljivost & $0.72(0.57,0.92)$ & $0.007^{*}$ \\
\hline 5. Dental cavities ${ }^{x}$ dryness of mouth $\bullet$ karijes ${ }^{x}$ suhoća usta & $0.98(0.76,1.27)$ & 0.884 \\
\hline 6. Malodor ${ }^{\mathrm{x}}$ dryness of mouth $\bullet$ zadah $^{\mathrm{x}}$ suhoća usta & $1.06(0.82,1.37)$ & 0.632 \\
\hline 7. Malodor ${ }^{\mathrm{x}}$ Sensitivity $\bullet$ zadah $^{\mathrm{x}}$ osjetljivost & $0.83(0.65,1.06)$ & 0.134 \\
\hline 8. Malodor ${ }^{\mathrm{x}}$ pain $\bullet$ zadah $^{\mathrm{x}}$ bol & $0.71(0.55,0.93)$ & $0.012^{*}$ \\
\hline 9. Malodor ${ }^{\mathrm{x}}$ bleeding gums $\bullet$ zadah $^{\mathrm{x}}$ krvarenje desni & $1.15(0.88,1.49)$ & 0.300 \\
\hline
\end{tabular}

Table 5 Final Model Backward LR: Predictors of routine dental check-up among male adolescents

Tablica 5. Konačni reverzni model LR: čimbenici rutinskih posjeta stomatologu među mladićima u pubertetu

\begin{tabular}{l|c|c}
\multicolumn{1}{c|}{ Variables $\bullet$ Varijable } & $\begin{array}{c}\text { Un-adjusted OR } \\
\text { Neprilagodeni OR } \\
(\mathbf{9 5 \%} \mathbf{C I})\end{array}$ & P-value $\bullet$ P-vrijednost \\
\hline Dental cavities $\bullet$ Karijes & $0.42(0.27,0.66)$ & $<0.001^{*}$ \\
\hline Malodor $\bullet$ Zadah & $0.45(0.25,0.78)$ & $0.005^{*}$
\end{tabular}

tions of dental problems with routine dental visits from final multivariable logistic regression model are shown in Table 4. Dental cavities and malodor $(\mathrm{P}<0.001)$, dental cavities and bleeding gums $(\mathrm{P}<0.006)$, dental cavities and sensitivity $(\mathrm{P}<0.007)$, dental cavities and pain $(\mathrm{P}<0.001)$, and malodor and pain (P 0.012) showed significant interactions with toloških problema $s$ rutinskim stomatološkim posjetima iz konačnoga multivarijantnog logističkog regresijskog modela prikazano je u tablici 4. Karijes i zadah $(\mathrm{P}<0,001)$, karijes i krvarenje $(\mathrm{P}<0,006)$, karijes i osjetljivost $(\mathrm{P}<0,007)$, karijes i bol $(\mathrm{P}<0,001)$ te zadah i bol $(\mathrm{P} 0,012)$ pokazali su značajne interakcije $s$ rutinskim stomatološkim pregledima. Inte- 
routine dental check-ups. The interaction of dental cavities and malodor with routine dental check-up demonstrated that inequity in routine dental check-up between those who had dental cavities and malodor than those who did not have dental cavities and malodor. In other words, dental cavities mediated the relationship between oral malodor and routine check-up. Similarly, significant interactions of other dental problems were demonstrated in the study.

The results of final "best model" using backward LR selection method are presented in Table 5. After controlling for other covariates in the model, having dental cavities $(\mathrm{OR}=0.42$, $95 \% \mathrm{CI}=0.27,0.66)$ and malodor $(\mathrm{OR}=0.45,95 \% \mathrm{CI}=0.25$, 0.78 ) were significantly associated with lower odds of visiting dental office for regular dental check-up (Table 5).

\section{Discussion}

The study investigated the factors associated with routine dental visits among schoolchildren and demonstrated that dental cavities and oral malodor were significantly associated with lower odds of visiting a dental office. Bivariate and multivariable logistic regression analyses failed to identify socioeconomic factors as significant predictors of routine dental attendance in our study. These significant study findings underscore the importance of raising awareness about visiting the dentist for routine dental check-up, particularly among children with dental conditions. This also reflects that children with oral problems are more likely to further deteriorate their oral health by not visiting the dentist for routine dental check-up.

In New Zealand, the prevalence of routine dental attendance during previous year was $82.1 \%$ among children aged 15 years (1). Similarly, 77\% of Aboriginal Australian children visited the dentist for a regular check-up during the past 12 months; however, this prevalence figure fell to 53\% during the last six months (13). In contrast, the present study showed that $18.9 \%$ of children performed routine dental visit during previous year. Likewise, even a lower prevalence of routine dental visits (9.3\%) among schoolchildren aged 1314 years was reported in a previous study from the Eastern province of Saudi Arabia (16). These variations in the prevalence of routine dental visit in different populations can be attributed to parental education, family income, oral health awareness, availability of insurance coverage, and access to healthcare services $(13,14,17)$. Nevertheless, our study findings call for increasing the awareness about the significance of routine dental attendance among adolescents in the country.

The literature shows improved oral health outcomes among individuals with regular dental attendance. Routine attenders exhibit an improved self-perceived and clinical oral health demonstrated by low caries experience and fewer tooth loss due to caries $(1,4)$. A recent study from the Eastern province of Saudi Arabia also reported lower odds of dental pain associated with routine dental check-ups among 6-12 years old schoolchildren (18). Similarly, a previous study from Brazil observed positive self-perception of oral health associated with the habit of visiting the dentist for a regular dental check-up (5). Furthermore, a routine dental atten- rakcija karijesa i zadaha s rutinskim stomatološkim pregledima pokazala je nejednakost u rutinskom pregledima između onih koji imaju karijes i zadah u odnosu prema onima koji nemaju. Drugim riječima, karijes je posredovao u odnosu između neugodnog zadaha i rutinskih pregleda. Slično tomu, $\mathrm{u}$ istraživanju su dokazane značajne interakcije ostalih stomatoloških problema.

Rezultati konačnoga najboljeg modela, korištenjem reverzne LR metode odabira, prikazani su u tablici 5. Nakon kontrole za druge kovarijante u modelu, prisutnost karijesa (OR $=0,42,95 \% \mathrm{CI}=0,27,0,66) \mathrm{i}$ zadaha $(\mathrm{OR}=0,45,95 \% \mathrm{CI}$ $=0,25,0,78)$ bila je statistički značajno povezana $s$ manjim izgledima za posjet stomatološkoj ordinaciji zbog redovitoga stomatološkog pregleda (tablica 5.).

\section{Rasprava}

$\mathrm{U}$ istraživanju su analizirani čimbenici povezani s rutinskim posjetima školske djece stomatologu te se pokazalo da su karijes i zadah statistički značajno povezani s manjim izgledima za odlazak doktoru dentalne medicine. U ovom istraživanju se analizom bivarijantne i multivarijantne regresije nije uspjelo identificirati socijalno-ekonomske čimbenike kao značajne pokazatelje za rutinske posjete stomatologu. Ovi nalazi ističu važnost podizanja svijesti o posjetu stomatologu radi rutinskoga pregleda, posebno među djecom s patološkim stanjima. To se također odražava na vjerojatnost da će djeca s oralnim problemima dodatno pogoršati svoje oralno zdravlje ako ne odu stomatologu radi redovitog pregleda.

U Novom Zelandu je učestalost rutinskih stomatoloških posjeta protekle godine bila $82,1 \%$ među djecom u dobi od 15 godina (1). Slično tomu, $77 \%$ djece australskih Aboridžina posjetilo je stomatologa zbog redovitog pregleda tijekom posljednjih 12 mjeseci, no taj se broj prevalencije smanjio na $53 \%$ u posljednjih šest mjeseci (13). Suprotno tomu, ovo istraživanje pokazalo je da je 18,9 \% djece obavljalo rutinske stomatološke preglede tijekom protekle godine. Isto tako, čak i manja prevalencija rutinskih posjeta stomatologu $(9,3 \%)$ zabilježena je među školarcima u dobi od 13 do14 godina u istraživanju provedenom u Istočnoj pokrajini Saudijske Arabije (16). Te varijacije u učestalosti rutinskih posjeta stomatologu u različitim populacijama mogu se pripisati obrazovanju roditelja, obiteljskom prihodu, svijesti o oralnome zdravlju, dostupnosti osiguranja i pristupu zdravstvenim uslugama $(13,14,17)$. Ipak, nalazi u našem istraživanju zahtijevaju povećanje svijesti o važnosti rutinskih stomatoloških posjeta među adolescentima u zemlji.

Literatura pokazuje poboljšane rezultate oralnoga zdravlja među pojedincima koji redovito posjećuju stomatologa. Redoviti pacijenti imaju bolje samoopažanje i kliničko oralno zdravlje, što se očituje u manjem broju karijesa i manjem gubitku zuba zbog karijesa $(1,4)$. U nedavnom istraživanju provedenom u Istočnoj pokrajini Saudijske Arabije također je uočena manja vjerojatnost zubobolje povezane s rutinskim stomatološkim pregledima među učenicima od 6 do 12 godina (18). Slično tomu, u istraživanju iz Brazila istaknuta je pozitivna percepcija oralnoga zdravlja povezana $s$ navikom posjećivanja stomatologa zbog redovitih pregleda (5). 
dance and improved oral health behaviors have considerable effects on oral health-related quality of life (6). In the present study, poor oral health shown by dental cavities and oral malodor were significantly associated with lower odds of performing routine dental visits. In addition, poor regular attendance among our study participants with dental cavities can be related to dental anxiety which can arise from anesthetic injections and drilling of teeth during treatment (19). It is known that dental anxiety affects oral care seeking behaviors and it is more prevalent among those who perform irregular dental visits than those who visit dentist regularly (20). A recent study observed significantly higher dental anxiety score among those subjects who avoid visiting dental office (21).

On the other hand, the results of a previous study showed that good oral health demonstrated by not having oral health problems including being caries-free increased the likelihood of dental attendance for routine check-up in Aboriginal Australians (3). This reflects that individuals with improved oral health have healthy preventive behaviors particularly better healthcare seeking practices, whereas those who have poor oral health status demonstrate poor health-related behaviors. A possible explanation for better oral health and preventive behavior including improved oral hygiene could be related to oral health advice and dental care received from a dental professional during a routine dental visit (3).

Family income and parental education are used to determine socioeconomic status (22). It is known that educated parents have improved knowledge and attitudes towards oral health which affect their children's oral health care behaviors (23). Similarly, family income determines access to oral care services because the cost of dental treatment is a major barrier to the provision of dental care $(24,25)$. Therefore, parents with high income and education pay greater attention to the oral health care of their children (26). In addition, parent's education and socioeconomic factors are also important for children's adherence to regular dental attendance (17). Interestingly, a previous study showed that children of mothers with low education were more likely to perform routine dental visits in Australia (13).

Although majority of children (68.9\%) had low family income, however, no significant associations of family income with routine dental attendance were observed in the present study. Similarly, our study found no significant influence of parental education on regular dental visits. These findings contradict the observations made by Camargo et al. who identified higher education of mother and high economic status as major predictors of regular dental attendance in Brazilian children (14). It is known that more dental visits for symptomatic relief are made by the children of low educated mother than those with university educated mothers (26). Low education attainment and low household income are associated with increased likelihood of not performing dental visits within last one year or visiting the dentist for emergency care (27). Likewise, underprivileged children also demonstrate poor regular attendance pattern and it was found that $50.3 \%$ of low-income children compared with $77.7 \%$ of children from middle and high income were regular attenders (28).
Nadalje, rutinski odlazak stomatologu i poboljšano oralno zdravlje znatno utječu na kvalitetu života povezanu s oralnim zdravljem (6). U ovom istraživanju loše oralno zdravlje i karijesi bili su statistički znatno povezani $s$ manjim izgledom za rutinske posjete stomatologu. $\mathrm{Uz}$ to, neredoviti odlasci stomatologu mogu biti povezani s dentalnom anksioznošću koja može nastati zbog ubrizgavanja anestetika i bušenja zuba tijekom liječenja (19). Poznato je da dentalna anksioznost utječe na traženje stomatološke skrbi i da je češća kod onih koji neredovito posjećuju liječnika dentalne medicine (20). U nedavnom istraživanju zabilježena je znatno veća dentalna anksioznosti kod onih koji izbjegavaju posjete stomatologu (21).

Istodobno, rezultati prethodnog istraživanja pokazali su da je dobro oralno zdravlje, tj. stanje bez zdravstvenih problema u usnoj šupljini, uključujući i karijes, povećalo vjerojatnost rutinskih stomatoloških posjeta kod Aboridžina u Australiji (3). To pokazuje da pojedinci s boljim oralnim zdravljem imaju zdravo preventivno ponašanje, posebno kad je riječ o traženju zdravstvene skrbi, a oni s lošim oralno-zdravstvenim statusom imaju loše zdravstveno ponašanje. Moguće objašnjenje boljega oralnog zdravlja i preventivnog ponašanja, uključujući poboljšanu oralnu higijenu, moglo bi biti povezano sa savjetima o oralnome zdravlju i higijeni koje su dobili od stomatologa tijekom rutinskog pregleda (3).

Obiteljski dohodak i obrazovanje roditelja koriste se za odredivanje socijalno-ekonomskog statusa (22). Poznato je da obrazovani roditelji imaju veće znanje i bolje stajalište o oralnome zdravlju, što utječe na oralno-zdravstvenu zaštitu njihove djece (23). Slično tomu, obiteljski dohodak određuje pristup stomatološkim uslugama jer troškovi takva liječenja velika su prepreka $(24,25)$. Zato roditelji s visokim primanjima i obrazovanjem posvećuju veću pozornost oralno-zdravstvenoj zaštiti svoje djece (26). Uz to, obrazovanje roditelja i socijalno-ekonomski čimbenici također su važni za redovite odlaske djece stomatologu (17). Zanimljivo je da je jedno istraživanje u Australiji pokazalo kako je vjerojatno da će djeca majki s nižim obrazovanjem češće obavljati rutinske stomatološke posjete (13).

Iako je većina djece $(68,9 \%)$ bila iz obitelji s niskim prihodima, u ovom istraživanju nije uočena značajnija povezanosti između obiteljskog dohotka $s$ rutinskih posjeta stomatologu. Slično tomu, u našem istraživanju nije uočen znatan utjecaj obrazovanja roditelja na redovite posjete stomatologu. Ta otkrića u suprotnosti su s opažanjima Camarga i suradnika koji su istaknuli visoko obrazovanje majke i visok ekonomski status kao glavne čimbenike za redovite posjete stomatologu, kad je riječ o brazilskoj djeci (14). Poznato je da više stomatoloških posjeta radi olakšanja simptoma obavljaju djeca majki $s$ niskim stupnjem obrazovanja od onih sa završenim fakultetom (26). Nizak stupanj obrazovanja i niski prihodi u kućanstvu povezani su s povećanom vjerojatnošću da nije obavljen posjet stomatologu u prethodnoj godini ili posjet stomatologu zbog hitne pomoći (27). Siromašna djeca također pokazuju loš obrazac u redovitim posjetima i utvrđeno je da je 50,3 $\%$ njih iz obitelji s niskim primanjima u usporedbi sa 77,7 $\%$ djece iz obitelji sa srednjim i visokim primanjima redovito odlazilo stomatologu (28). 
Multistage random sampling and adequate sample size in the present research provides reliable evidence about the low probability of performing routine dental visits among adolescents with dental problems. The significant study findings highlight unhealthy oral care seeking behavior that can worsen oral health of those children who already have oral problems. There are certain limitations of the study which are 1) inclusion of male study participants, 2) a cross-sectional study design, 3) self-reported oral conditions, and 4) data collection from public schools in urban locations. The cultural norms in the country do not favor data collection by male researchers from female institutions. The cross-sectional study design precludes a causal inference of results. There is a possibility of inaccuracy in self-reported data of oral conditions. The inclusion of data from male participants and from schools in urban locations can compromise the generalizability of study findings. Moreover, the influence of dental anxiety on dental visits was not evaluated in the study because primary data did not include dental anxiety. In the future, a large multicenter clinical study should include examination of oral conditions and recording of routine dental visits by adolescents.

\section{Conclusions}

The study demonstrated a low prevalence of routine dental visits among schoolchildren. Dental problems, particularly dental cavities and tooth sensitivity were highly prevalent. The children with dental cavities and malodor were less likely to visit dental office for routine dental check-up than those without dental cavities and malodor. No significant influence of socioeconomic factors on routine dental attendance was observed. Given the high prevalence of oral disease and low routine dental check-up, the study findings are significant for the prevention of oral problems through the promotion of routine dental attendance.

Oral health campaigns should raise awareness about the significance of routine dental check-up for the maintenance of oral health in schoolchildren. Healthcare professionals should provide advice, particularly to children with dental cavities and oral malodor to regularly visit the dentist to maintain optimal oral health. Decision makers in healthcare organizations should use these findings for policy development to reduce the burden of oral disease among adolescents.

\section{Acknowledgement}

The author is grateful to dental interns for their great help in data collection.

\section{Conflicts of interest}

There are no conflicts of interest. No financial support and sponsorship
Višestupanjsko slučajno uzorkovanje i odgovarajuća veličina uzorka u ovom istraživanju omogućili su pouzdane dokaze o maloj vjerojatnosti u obavljanju rutinskih stomatoloških posjeta kod adolescenata sa stomatološkim problemima. Značajni nalazi istraživanja ističu lošu stomatološku skrb koja može pogoršati oralno zdravlje one djece koja već imaju takve probleme. Postoje određena ograničenja u istraživanju, a to su: 1) uključivanje samo dječaka i mladića; 2) presječna studija; 3) samoprocjena oralno-zdravstvenoga stanja ; 4) prikupljanje podataka iz javnih škola u gradovima.

Kulturne norme u zemlji ne odobravaju da podatke u ženskoj populaciji prikupljaju muškarci. Dizajn poprečnoga presjeka sprječava kauzalni zaključak. Postoji mogućnost da su, zbog samoprocjene, netočni podatci o oralno-zdravstvenome stanju. Uključivanje podataka mladića i škola iz gradova može ugroziti opću primjenjivost nalaza istraživanja. Nadalje, utjecaj dentalne anksioznosti nije procijenjen u istraživanju jer primarni podatci nisu uključivali takvu anksioznost. U budućnosti bi velika multicentrična klinička istraživanja trebala uključivati analizu oralno-zdravstvenoga stanja i zabilježiti rutinske posjete adolescenata stomatologu.

\section{Zaključci}

Studija je pokazala nisku prevalenciju rutinskih posjeta stomatologu među školarcima. Dentalni problemi, posebno karijes i osjetljivost zuba, bili su vrlo česti. Djeca s karijesom i neugodnim zadahom rjeđe su posjećivala stomatološke ordinacije u sklopu redovitih pregleda od one bez tih neugodnih pojava. Nije uočen značajan utjecaj socijalno-ekonomskih čimbenika na rutinsku stomatološku skrb. S obzirom na veliku prevalenciju oralnih bolesti i rijetke redovite preglede, nalazi istraživanja važni su za prevenciju oralnih problema i promicanje rutinskih posjeta stomatologu.

Akcije za promicanje oralnoga zdravlja trebale bi podignuti svijest o značenju rutinskih stomatoloških pregleda zbog održavanja oralnoga zdravlja kod školske djece. Zdravstveno osoblje treba savjetovati, osobito djecu s karijesima i neugodnim zadahom, da redovito posjećuju stomatologa radi održavanja optimalnoga oralnog zdravlja. Donositelji odluka u zdravstvenim organizacijama trebali bi se koristiti ovim nalazima za projekte kojima bi se smanjila prevalencija oralnih bolesti među adolescentima.

\section{Zahvala}

Autor zahvaljuje stažistima na velikoj pomoći pri prikupljanju podataka.

\section{Sukob interesa}

Nema sukoba interesa - nije bilo ni financijske potpore, ni sponzorstva. 


\section{Sažetak}

Cilj: Željela se procijeniti povezanost socijalno-ekonomskih čimbenika i samopercipiranih oralnih stanja s rutinskim stomatološkim pregledima među mladićima u pubertetu. Metode: Ovo presječno istraživanje provedeno je na mladićima (od 10. do 12. razreda) iz javnih škola u različitim gradovima u istočnoj pokrajini Saudijske Arabije. Za odabir sudionika primijenjeno je višestupanjsko randomizirano uzorkovanje. Za prikupljanje podataka korišten je pilotirani upitnik preveden na arapski jezik. Rezultat: Bilo je uključeno 586 učenika prosječne dobi 16,86 $\pm 0,87$ godina. Prevalencija rutinskih posjeta stomatologu tijekom prethodne godine iznosila je $18,9 \%$. Kod polovine cjelokupnog uzorka zabilježeni su karijes (50,5\%) i osjetljivost zuba (50\%) praćena bolovima $(42,2 \%)$. Bivarijantna analiza otkrila je da su djeca s karijesima (ILO 0,4, $95 \% \mathrm{Cl} 0,26,0,61)$, zuboboljom (OR 0,63, $95 \% \mathrm{Cl}$ $0,41,0,97)$ i zadahom (IL $0,41,95 \% \mathrm{Cl} 0,23,0,71$ ) rjeđe odlazila na rutinske stomatološke preglede od onih bez navedenih stanja. Konačni model multivarijantne logističke regresije pokazao je da su karijes $(\mathrm{OR} 0,42,95 \% \mathrm{Cl} 0,27,0,66)$ i zadah $(\mathrm{OR} 0,45,95 \% \mathrm{Cl} 0,25,0,78)$ statistički značajno povezani s rjeđim posjetima doktoru dentalne medicine radi redovitih pregleda. Nije uočen znatan utjecaj socijalno-ekonomskih čimbenika na rutinske odlaske stomatologu. Zaključci: Mali broj mladića odlazio je na rutinske stomatološke preglede. Djeca s karijesom i neugodnim zadahom rjeđe su to činila. Treba povećati svijest o važnosti redovitih stomatoloških pregleda kako bi se kod školske djece smanjila prevalencija oralnih bolesti.
Zaprimljen: 19. ožujka 2019.

Prihvaćen: 28. srpnja 2019.

Adresa za dopisivanje

Muhammad Ashraf Nazir, BSc, BDS,

$\mathrm{MPH}, \mathrm{FRSPH}$

Lecturer Dental Public Health,

Imam Abdulrahman Bin Faisal

University

College of Dentistry

Department of Preventive Dental

Science,

Dammam, Saudi Arabia.

P. O. Box 1982 Dammam 31441

mobitel: \#00966543579615

manazir@iau.edu.sa

Ključne riječi

stomatološka skrb; samoprocjena; socijalno-ekonomski čimbenici

\section{References}

1. Thomson WM, Williams SM, Broadbent JM, Poulton R, Locker D. Long-term dental visiting patterns and adult oral health. J Dent Res. 2010 Mar;89(3):307-11.

2. Oral Health in America: A Report of the Surgeon General. Rockville, MD: US Department of Health and Human Services, National Institute of Dental and Craniofacial Research, National Institutes of Health, 2000. NIH Publication no. 00-4713. 2014.

3. Amarasena N, Kapellas K, Skilton MR, Maple-Brown LJ, Brown $A$, Bartold $M$, et al. Factors associated with routine dental attendance among aboriginal Australians. J Health Care Poor Underserved. J Health Care Poor Underserved. 2016;27(1A):67-80.

4. Crocombe LA, Broadbent JM, Thomson WM, Brennan DS, Poulton R. Impact of dental visiting trajectory patterns on clinical oral health and oral health-related quality of life. Public Health Dent. 2012 Winter;72(1):36-44.

5. Afonso-Souza G, Nadanovsky P, Chor D, Faerstein E, Werneck GL, Lopes CS. Association between routine visits for dental checkup and self-perceived oral health in an adult population in Rio de Janeiro: the Pro-Saude Study. Community Dent Oral Epidemiol. 2007 Oct;35(5):393-400.

6. Almoznino G, Aframian DJ, Sharav Y, Sheftel Y, Mirzabaev A, Zini A. Lifestyle and dental attendance as predictors of oral health-related quality of life. Oral Dis. 2015 Jul;21(5):659-66.

7. Langevin SM, Michaud DS, Eliot M, Peters ES, McClean MD, Kelsey KT. Regular dental visits are associated with earlier stage at diagnosis for oral and pharyngeal cancer. Cancer Causes Control. 2012 Nov;23(11):1821-9.

8. Spalthoff S, Holtmann H, Krüskemper G, Zimmerer R, Handschel J, Gellrich NC et al. Regular Dental Visits: Influence on Health-Related Quality of Life in 1,607 Patients with Oral Squamous Cell Carcinoma. I Int I Dent. 2017;2017:9638345.

9. Locker D, Maggirias J, Quinonez C. Income, dental insurance coverage, and financial barriers to dental care among Canadian adults. J Public Health Dent. 2011 Fall;71(4):327-34.

10. Riley P, Worthington HV, Clarkson JE, Beirne PV. Recall intervals for oral health in primary care patients. Cochrane Database Syst Rev. 2013 Dec 19;(12):CD004346.

11. American Dental Association. How Often Should a Person Go to the Dentist? Questions About Going to the Dentist - Mouth Healthy. 2016. [cited 2017 Nov 4]. Available from: http://www. mouthhealthy.org/en/dental-care-concerns/questions-aboutgoing-to-the-dentist.

12. National Institue for Health and Care Excellence. Dental checks: intervals between oral health reviews. [cited 2017 Nov 4]. Available from: https://www.nice.org.uk/guidance/cg19.

13. John JR, Mannan H, Nargundkar S, D’Souza M, Do LG, Arora A. Predictors of dental visits among primary school children in the rural Australian community of Lithgow. BMC Health Serv Res. 2017 Apr $11 ; 17(1): 264$
14. Camargo MB, Barros AJ, Frazao P, Matijasevich A, Santos IS, Peres MA, et al. Predictors of dental visits for routine check-ups and for the resolution of problems among preschool children. Rev Saude Publica. 2012 Feb;46(1):87-97.

15. World Health Organization. Management of substance abuse, process of translation and adaptation of instruments. 2011. [cited 2017 Nov 13]. Available from: http://www.who.int/substance abuse/research_tools/translation/en/

16. Nazir MA. Patterns of dental visits and their predictors among male adolescents. Dent Med Probl. 2018 Apr-Jun;55(2):185-190.

17. Badri P, Saltaji H, Flores-Mir C, Amin M. Factors affecting children's adherence to regular dental attendance: a systematic review. J Am Dent Assoc. 2014 Aug;145(8):817-28.

18. AlHumaid J, El Tantawi M, AlAgl A, Kayal S, Al Suwaiyan Z, Al-Ansari A. Dental visit patterns and oral health outcomes in Saudi children. Saudi J Med Med Sci. 2018 May-Aug;6(2):89-94.

19. Shim YS, Kim AH, Jeon EY, An SY. Dental fear \& anxiety and dental pain in children and adolescents; a systemic review. J Dent Anesth Pain Med. 2015 Jun;15(2):53-61.

20. Quteish Taani DS. Dental anxiety and regularity of dental attendance in younger adults. J Oral Rehabil. 2002 Jun;29(6):604-8.

21. Appukuttan DP, Cholan PK, Tadepalli A, Subramanian S. Evaluation of Dental Anxiety and its Influence on Dental Visiting Pattern among Young Adults in India: A Multicentre Cross Sectional Study. Ann Med Health Sci Res. 2017;7(6):11-23.

22. Braveman PA, Cubbin C, Egerter S, Chideya S, Marchi KS, Metzler $M$, et al. Socioeconomic status in health research: one size does not fit all. J JAMA. 2005 Dec 14;294(22):2879-88.

23. Al-Omiri MK, Al-Wahadni AM, Saeed KN. Oral health attitudes, knowledge, and behavior among school children in North Jordan. J Dent Educ. 2006 Feb;70(2):179-87.

24. Bhatti T, Rana Z, Grootendorst P. Dental insurance, income and the use of dental care in Canada. J Can Dent Assoc. 2007 Feb;73(1):57

25. Thompson B, Cooney P, Lawrence H, Ravaghi V, Quinonez C. Cost as a barrier to accessing dental care: findings from a Canadian population-based study. J Public Health Dent. 2014 Summer;74(3):210-8

26. Saldunaite K, Bendoraitiene EA, Slabsinskiene E, Vasiliauskiene I, Andruskeviciene $\mathrm{V}$, Zubiene J. The role of parental education and socioeconomic status in dental caries prevention among Lithuanian children. Medicina. Medicina (Kaunas). 2014;50(3):156-61.

27. Zangiabadi S, Costanian C, Tamim H. Dental care use in Ontario: the Canadian community health survey (CCHS). BMC Oral Health. 2017 Dec 29;17(1):165.

28. Lambert MJ, Vanobbergen JSN, Martens LC, De Visschere LMJ. Socioeconomic inequalities in caries experience, care level and dental attendance in primary school children in Belgium: a cross-sectional survey. BMJ Open. 2017 Jul 20;7(7):e015042. 